\title{
MATERIAIS DIDÁTICOS MANIPULÁVEIS: CONSTRUINDO UM PRISMA PENTAGONAL UTILIZANDO RECURSOS DE BAIXO CUSTO
}

\author{
MANIPULATEABLE TEACHING MATERIALS: BUILDING A PENTAGONAL PRISM \\ USING LOW-COST RESOURCES
}

Fayad Merched Chaar Filho ${ }^{1}$

Alan Gonçalves Lacerda ${ }^{2}$

RESUMO: Neste artigo tem-se como objetivo analisar e identificar as habilidades que podem trazer contribuições para alunos e professores para o ensino e aprendizagem de conceitos básicos de geometria espacial contextualizando nos elementos de um prisma pentagonal utilizando matérias didáticos manipuláveis de baixo custo. Para tanto, utiliza-se como referencial teórico os autores Santos e Costa (2020); Sousa, Silva e Silva (2020); Fonseca e Gualandi (2020); Girotto (2015); Dias (2012); Lorenzato (2006); entre outros que fomentam a importância dos materiais didáticos para o ensino de geometria. Para a realização do projeto, desenvolve-se uma atividade que possibilitava os alunos a construção de um sólido geométrico (prisma pentagonal). Este projeto foi aplicado a trinta alunos do $6^{\circ}$ ano, em uma escola do ensino fundamental no município de Breves-Pa. Os resultados apontaram que a utilização de materiais de baixo custo na construção de um prisma pentagonal contribui para a exposição de 1127 ideias e conjecturas acerca do prisma e suas nomenclaturas. A utilização de materiais de baixo custo, além de contribuir para o processo de aprendizagem, contribui também para o processo de ensino, pois os materiais passam ser mais acessível para o planejamento de uma aula enriquecedora.

Palavras-chave: Prisma. Construção. Ensino. Aprendizagem.

ABSTRACT : This article aims to analyze and identify the skills that can bring contributions to students and teachers for teaching and learning basic concepts of spatial geometry contextualizing the elements of a pentagonal prism using low-cost manipulative didactic materials. Therefore, the authors Santos and Costa (2020) are used as a theoretical framework; Sousa, Silva and Silva (2020); Fonseca and Gualandi (2020); Girotto (2015); Days (2012); Lorenzato (2006); among others that promote the importance of teaching materials for the teaching of geometry. To carry out the project, an activity was developed that enabled students to build a geometric solid (pentagonal prism). This project was applied to thirty 6 th grade students in an elementary school in the city of Breves-Pa. The results showed that the

\footnotetext{
${ }^{1}$ Fayad-chaar@hotmail.com

2acerda.ag@gmail.com
} 
use of low cost materials in the construction of a pentagonal prism contributes to the exposition of ideas and conjectures about the prism and its nomenclatures. The use of lowcost materials, in addition to contributing to the learning process, also contributes to the teaching process, as the materials become more accessible for planning an enriching class.

Keyword: Prism. Construction. Teaching. Learning.

\section{INTRODUÇÃO}

O material didático manipulável vem cada vez mais ganhando espaço dentro da sala de aula de matemática, autores como Santos e Costa (2020) e Sousa, Silva e Silva (2020) corroboram da importância destes, para a contribuição na interação, exposição de ideias e manuseios dentro da sala de aula, pois acreditam que isso visa contribuir para a autonomia e a criticidade dos alunos.

Nesse sentido, aborda-se o material didático manipulável nas perspectivas de Lorenzato (2006), em que enfatiza a importância do Laboratório de Ensino de Matemática (LEM), que para ele, é um espaço onde os professores de matemática tornam os conteúdos matemáticos mais compreensivos para os alunos, bem como a importância desse ambiente para o processo de ensino.

Nesse ambiente do processo de ensino, está presente a investigação matemática, onde o professor é o mediador desse processo, proporcionando aos alunos momentos de interações, argumentação e exposições de ideias para o desenvolvimento da autonomia dos alunos. (DIAS, 2012)

Diante disso, o uso do material didático manipulável se torna imprescindível nas abordagens metodologias dos professores. Lorenzato (2006) enfatiza ainda que o uso desses materiais concretos contribui para uma aprendizagem ativa dos alunos, além de auxiliar na transição da aprendizagem concreta para abstrata. Busca-se enfatizar aqui, que se entende a construção dos matérias didáticos como uma investigação matemática, em que visa proporcionar aos alunos momentos de investigações na busca de soluções, ao desconhecido. (PONTE, 2014). 
Nesta perspectiva, objetiva-se explorar a construção de um prisma pentagonal utilizando materiais concretos de baixo custo, como papel, régua, cola e tesoura. Para buscarse nortear o referido trabalho, propõem-se a seguinte questão de pesquisa: Quais os conceitos $e$ habilidades matemáticos que os alunos do $6^{\circ}$ ano recorrem na construção de um prisma utilizando materiais didáticos manipuláveis?

Para isso, objetiva-se analisar e identificar as habilidades desenvolvidas pelos alunos na construção do sólido geométrico. Esta construção se deu por meio de materiais de baixo custo que podem proporcionar aos professores e alunos caminhos alternativos para o processo de ensino e aprendizagem da matemática.

\section{O MATERIAL DIDÁTICO MANIPULÁVEL E A INVESTIGAÇÃO MATEMÁTICA}

Os materiais didáticos manipuláveis constituem uma importante ferramenta para o processo de ensino e aprendizagem dentro da sala de aula de matemática, podendo ser qualquer ferramenta útil à mediação desses processos, como por exemplo: pode ser um jogo, uma calculadora, um computador, um livro, um filme, entre outros. Estes materiais didáticos manipuláveis podem facilitar as observações, análises, desenvolver o raciocínio lógico e crítico, além de auxiliar o aluno na construção dos seus conhecimentos (TURRIONI; PEREZ, 2006).

Para Serrazina (1991, p. 37), os materiais manipuláveis são "objectos, instrumentos que podem ajudar os alunos a descobrir, a entender ou consolidar conceitos fundamentais nas diversas fases da aprendizagem”. Já para Jacobs (1987), são objetos usados pelos alunos que lhes permitem aprender ativamente determinado conceito.

Já Lorenzato (2006) apresenta algumas estruturas para proporcionar um ensino e aprendizado favorável mediante o uso dos materiais manipuláveis. Para o supracitado autor, é importante ter um ambiente propício, onde os professores possam organizar, planejar e fazer acontecer com que os alunos pensem matematicamente.

Nessa acepção, é muito importante que os alunos começassem a pensar de forma matemática desenvolvendo suas competências e habilidades que contribuam para o processo 
de aprendizagem, pois os alunos começaram a explorar suas ideias, bem como questionar, conjecturar, procurar, experimentar, analisar e concluir. (LORENZATO, 2006).

Lorenzato (2006) destaca sete habilidades que podem ser desenvolvidas na manipulação de materiais dentro da sala de aula de matemática: i) ampliação da linguagem matemática; ii) estratégias de resolução de problemas; iii) desenvolver estimativas e cálculos mentais; iv) métodos de investigação cientifica; v) estimular concentração, perseverança, raciocínio e criatividade; vi) troca de ideias; vii) estimular compreensão de regras.

A ampliação da linguagem (i) dentro da sala de aula contribui para uma melhor exploração da comunicação, onde os alunos adquirem a capacidade de se comunicar matematicamente. Ponte et al (2007, p. 4) coloca a característica da comunicação matemática como a "aquisição de uma organização complexa de símbolos, signos e representações matemáticas”. Já a autora Rodrigues (2019) enfatiza que a linguagem matemática se constitui numa das variáveis que interfere no processo de ensino e de aprendizagem da matemática, onde os alunos aprendem a converter situações-problemas que são compreendidas da linguagem natural para a linguagem matemática.

Diante disso, a ampliação da linguagem pode contribui para as elaborações de 1130 estratégias de resoluções (ii), pode-se utilizar os seguintes procedimentos para solucionar problemas matemáticos, como:

Retomar os elementos enunciados (dados do problema), atribuir significado a esses elementos, traduzindo-os para a linguagem matemática; acrescentar informações (conhecimentos prévios); estabelecer planos de resolução; aplicar os conhecimentos matemáticos nesses planos; e verificar a solução, retornando ao texto inicial. (LORENSATTI, 2009, p. 95)

Nesta perspectiva, os alunos também desenvolvem estimativa de projeção (iii), onde eles podem analisar como um determinado problema pode ser resolvido, apresentando e expondo seus cálculos mentais em busca da solução do problema. Ananias e Pessoa (2015, p. 39) explanam que:

O cálculo mental é um procedimento ágil, que favorece a autonomia, a partir do momento em que permite à criança ser ativa e criativa nas escolhas dos caminhos para chegar ao valor final, já que existem diferentes maneiras de calcular e ela pode escolher a que melhor se adapta a uma determinada situação. 
Essa autonomia dos alunos se reflete em suas resoluções de problemas, passando a investigar métodos que consolidam seus cálculos mentais, e isso, aliado a utilização do material didático manipulável, pode auxiliar e contribuir para seu processo de aprendizagem.

Assim, o método de investigação (iv) se faz muito presente nesse contexto, pois os alunos passam a investigar soluções, construindo estratégias e as validando. Ponte et al (1998, p. 7) ressalta que para propiciar este momento investigativo, o professor "tem de criar um ambiente em que todos os alunos se sintam à vontade para apresentar as suas conjecturas, argumentar contra ou a favor das ideias dos outros, sabendo que o seu raciocínio será valorizado". Desta forma, os alunos podem expor suas opiniões e formas de resoluções perante a turma.

Nesse viés, os professores passam a promover em seus alunos a estimulação de suas criatividades ( $v$ ), ou seja, os alunos começam a ser autônomos, construindo formulas, macetes e estratégias que estimulem essa criatividade e criticidade sobre o uso dos materiais didáticos manipuláveis.

Durante esses processos, na troca de ideias (vi), o professor pode formular perguntas que permitem aos alunos exporem suas opiniões, tanto com o professor, quanto com seus colegas de turma. Nesse momento que ocorre essa troca de informação, os alunos passam a se 1131 conscientizar, mediante ao material didático, sobre sua importância para o dia a dia. $\mathrm{O}$ autor Ponte et al (1998, p. 13) fala que a troca de "ideias matemáticas se desenvolvem como fruto das tentativas de compreensão, como resposta a problemas e necessidades experimentadas pelo próprio aluno", ou seja, encontrar o entendimento de um significado matemático, contribui diretamente nesse processo de comunicação através dos materiais manipuláveis.

Por último, Lorenzato (2006) destaca a estimulação da compreensão (vii) de conceitos matemáticos que ocorre por meio dos materiais didáticos manipuláveis, onde os alunos podem analisar e discutir conceitos como nomenclaturas, aresta, vértice, face e volume.

Passos (2006, p. 8I) fala que:

Os conceitos matemáticos que eles devem construir, com a ajuda do professor, não estão em nenhum dos materiais de forma a ser abstraídos deles empiricamente. Os conceitos serão formados pela ação interiorizada do aluno, pelo significado que dão às ações, às formulações que enunciam, às verificações que realizam. 
Essa perspectiva, compreende um processo de investigação na matemática, Dias (2012) destaca que nesse processo o professor desenvolve um papel regulador de mediador, essencial no sentido de assegurar ao aluno, através de suas intervenções, a oportunidade de compreender o significado das tarefas e aprender a realizá-las com autonomia.

Ponte (2003, p. 2) fala que um processo é dado como investigativo:

[...] quando formulamos as nossas próprias questões e procuramos responder-lhes, de modo tanto quanto possível fundamentado e rigoroso. Em contextos de ensino, aprendizagem ou formação, investigar não significa necessariamente lidar com problemas na fronteira do conhecimento nem com problemas de grande dificuldade. Significa, apenas, trabalhar a partir de questões que nos interessam e que se apresentam inicialmente confusas, mas que conseguimos clarificar e estudar de modo organizado.

Nesse sentido, a construção de um material didático manipulável para o ensino de geometria por moldes investigativos, pode contribuir para esse processo de ensino e aprendizagem. Para Vale e Barbosa (2015, p. 14)

Os materiais manipuláveis podem ajudar na construção de conceitos e na resolução de problemas de matemática, devem ser usados quando forem necessários, independentemente da idade dos alunos, e têm potencialidades e fragilidades que os professores devem saber identificar. Embora a investigação apóie esta idéia nem todos os temas, nem todos os alunos beneficiam do recurso a materiais manipuláveis.

Seguindo este raciocínio, os materiais didáticos manipuláveis “permitem a manipulação táctil do aluno, permitindo realizar construções e deformações de objetos geométricos" (LUCENA, 2017, p. 27). A construção e manipulação de materiais contribuem na autonomia e reflexão destes, para a evolução dos alunos no que se tangia o desenvolvimento como construção de identidade.

Assim, o uso do material didático manipulável por meio dos materiais de baixo custo na construção de um prisma pentagonal, pode auxiliar na construção dos conceitos e nomenclaturas básicos dessa figura geométrica, fazendo que os alunos exponham suas ideias e conjecturas, bem como contribuam para o processo de ensino e aprendizagem dos educandos na sala de aula de matemática. 


\section{MATERIAIS E MÉTODOS}

O presente trabalho de cunho qualitativo teve como objetivo analisar e discutir as compreensões dos alunos e suas contribuições frente a construção de um sólido geométrico (prisma pentagonal). Para isso, realizar uma tarefa que proporciona aos alunos um momento de investigação na construção deste sólido. Nesse trabalho, teve a contribuição de 30 alunos de uma turma do 6으 ano de uma escola do ensino fundamental no município de Breves - PA.

A elaboração da tarefa perpassou por cinco etapas nas quais será elencado, a saber: na primeira, busca-se dialogar com a turma sobre seus conhecimentos prévios em geometria para analisar as suas compreensões sobre as formas geométricas, lhes ensinando as diferenças entre a geometria plana e espacial, enfatizando os conceitos de aresta, vértice, face e volume buscando diferenciar os contextos na sala de aula. Durante o diálogo, exibimos uma parte que corresponde a sete minutos do vídeo Donald no país da matemágica onde fala sobre formas geométricas, inclusive do pentágono que é a base do nosso prisma, com o intuito de visualizarem melhor o que havia dialogado.

$\mathrm{Na}$ segunda etapa, distribuímos a cada aluno uma folha de papel cartão já com o

desenho de um prisma planificado sobre ele, para recorte, além de tesoura, régua e cola. 1133 Posteriormente, pedimos para que os alunos recortassem e colassem o papel em busca da construção do sólido geométrico, e assim, pudessem manuseá-lo para relacionar a figura com o mundo físico. Durante esta etapa, auxilia os alunos nos recortes, dobragem e colagem do papel.

A terceira etapa, pedimos aos alunos que relatassem com suas próprias palavras, os significados e as nomenclaturas do sólido que construíram, ou seja, os alunos olhavam para o prisma e tentavam dar nomes técnicos aquilo que estavam vendo, como por exemplo: face, vértice, aresta e volume.

$\mathrm{Na}$ quarta etapa, distribuímos aos alunos um questionário para que respondessem e pudessem encontrar um significado mútuo em suas respostas. Esta tarefa foi aplicada com o intuito de alcançar aqueles possíveis alunos que teriam vergonha de se expressar, desta forma, escreveriam seus entendimentos no questionário, em seguida, teriam que ler ou expor suas 
respostas para a turma, pois é importante que eles deem suas opiniões e a exponham aos seus colegas como forma de interação. Veja a imagem da folha de questionário seguir.

Imagem 1 - Tarefa distribuída aos alunos

$\left.1^{\circ}\right)$ O que é aresta?

$\left.2^{\circ}\right)$ O que é vértice?

$\left.3^{\circ}\right) \mathrm{O}$ que é face?

$4^{\circ} \mathrm{O}$ que é volume?

Fonte: Autores

Na quinta e última etapa, após ouvir todas as respostas dos alunos, abrimos espaço para as discussões, onde os alunos poderiam discordar com a resposta de outro colega e justificar o porquê de estar discordando. Por fim, relata-se aos alunos onde mais poderia encontrar as arestas, vértices, face e volume e as outras diversas formas de um prisma.

\section{RESUlTADO E DISCUSSÃO}

Para analisar os resultados, será realizar discussões por etapas que transcorreram a tarefa, bem como também por analises de habilidades que podem vim a surge durante a utilização do material didático manipulável. A seguir, será analisada essas habilidades que podem ser 
evidenciadas durante a realização do uso do material didático manipulável segundo Lorenzato (2006).
i) ampliação da linguagem matemática;
ii) estratégias de resolução de problemas;
iii) desenvolver estimativas e cálculos mentais;
iv) métodos de investigação cientifica;
v) estimular concentração, perseverança, raciocínio e criatividade;
vi) troca de ideias;
vi) estimular compreensão de regras.

Observa-se a seguir a primeira etapa que é o primeiro contato com a turma mediante a construção dos conceitos básicos de geometria e suas formas.

Na primeira etapa, inicia-se um diálogo com a turma, onde pude-se elucidar a diferença entre uma figura geométrica plana e espacial. Para Fonseca, Brunheira e Ponte (1999) a apresentação da tarefa pode ser feita com mais ou menos informação, ou seja, pode falar para 1135 os alunos os moldes de como resolvera tarefa, ou deixá-los à vontade para que investiguem sem muitas informações, desta forma, a introdução da tarefa pode assumir a forma escrita, oral ou mista

Em tal caso, utilizando a forma mista de introdução, usa-se o exemplo de figura de geometria plana como sendo uma figura em que não se pode tocá-la ou manuseá-la, apenas sendo um fruto de nossa imaginação, totalmente abstrata, como exemplo, desenha-se um retângulo no quadro branco e explica que ele estaria em um plano de duas dimensões, não podendo ser tocado. Nessa introdução, além do desenho no quadro branco, também exibimos sete minutos de um vídeo aminado chamado Donald no país da matemágica que fala entre outras coisas das formas geométricas. 
Sendo assim, abrimos uma prévia para inserção da figura geométrica espacial, após o vídeo, utiliza-se como exemplo a sala de aula, explicando que ela seria palpável por conta de uma terceira dimensão.

Gradativamente, adentrando aos conceitos básicos de figura espacial, como a aresta, a face, o vértice e o volume, dando alguns exemplos, como uma bola de futebol, capa de um caderno, uma caneta, entre outros, para que pudesse chegar ao prisma pentagonal. Na conclusão deste diálogo mostra-se uma folha em branco de papel A4 para a turma e questionando oralmente se aquele objeto era de geometria plana ou espacial. Um aluno levantou a mão e respondeu que era de geometria plana, então nos reforça-se a diferença dizendo que: não seria objeto de geometria plana porque ele seria palpável, e que, por mais fina que fosse aquela folha, ainda assim ela teria uma espessura, ou seja, uma terceira dimensão, logo, sendo de geometria espacial.

Consequentemente, pode-se perceber que os alunos já começam a expor suas ideias utilizando a linguagem natural, isso traz contribuições na visão do Lorenzato (2006) que relata a ampliação da linguagem (i) por meio do material didático. Esse é um passo importante para o desenvolvimento da linguagem matemática.

A segunda etapa, que é a construção do prisma pentagonal, distribuímos aos alunos as folhas de papel cartão, tesouras, réguas e cola de papel para que pudessem construir o seu próprio material didático manipulável, como podem ver na imagem 2 que se segue.

Imagem 2 - Construção do prisma pentagonal

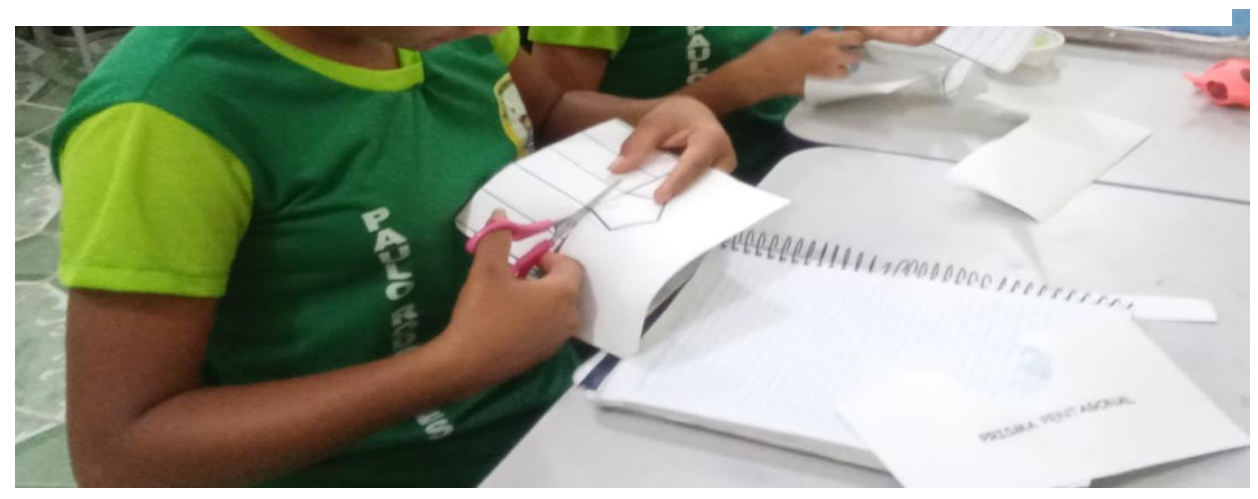

Fonte: Autores 
Analisando a imagem 2, os alunos começaram a construir seu próprio através dos materiais manipuláveis seu próprio sólido geométrico que seria o prisma pentagonal. Botas e Moreira (2013, p. 254) enfatiza que o contato com materiais pode "despertar interesse e envolver o aluno em situações de aprendizagem matemática, já que os materiais podem constituir um suporte físico através do qual as crianças vão explorar, experimentar, manipular e desenvolver a observação".

Com esse processo de construção do material didático manipulável, o Lorenzato (2006), salienta que é difícil construir algo sozinho, por isso é importante o trabalho em equipe, tanto entre alunos, quanto entre professores, pois isso contribui para construção do conhecimento dos alunos, sua identidade e criticidade na formação como cidadão, pois é fazendo que se aprende. A seguir, ver-se-á a construção desse material em equipe.

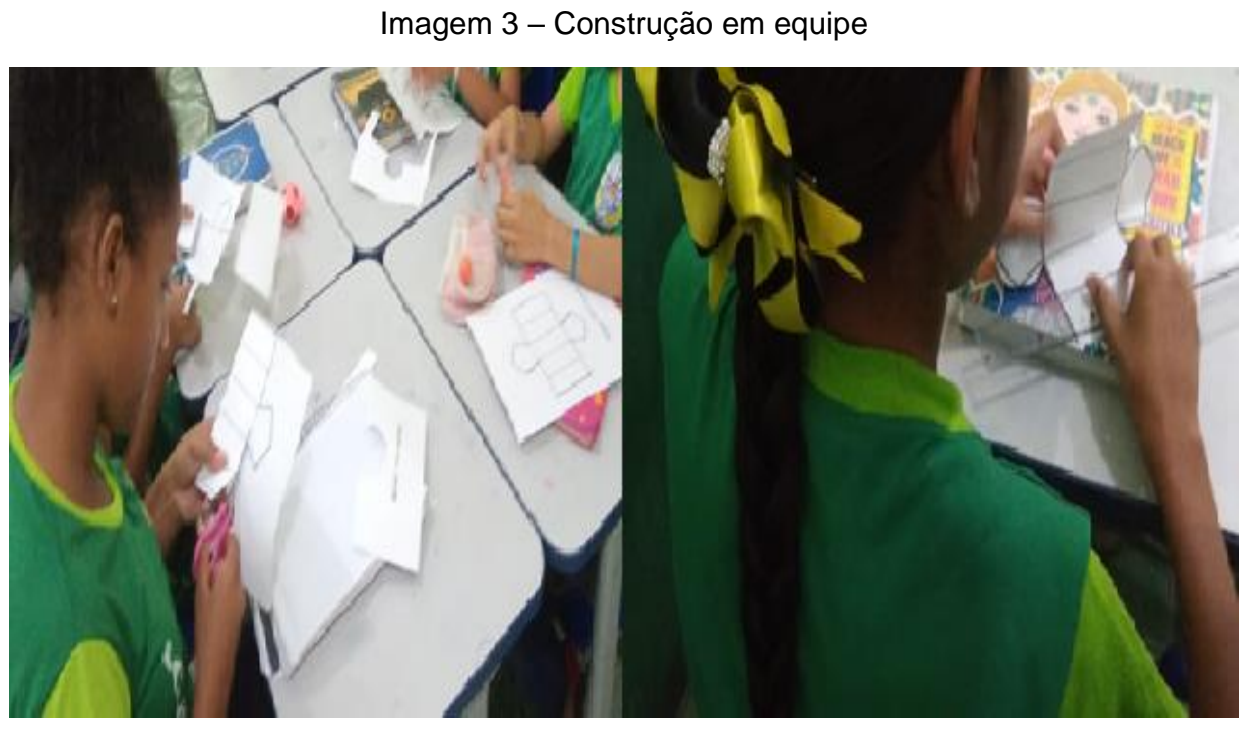

Fonte: Autores

Durante esse processo de construção, pode-se observar as elaborações de estratégias (ii) ditas por Lorenzato (2006), buscando encontrar a melhor maneira de construir e analisar como realizar um recorte podendo ficar cinco fáceis que são das laterais de um prisma pentagonal. 
Após a construção do material, inicia a terceira etapa do nosso trabalho, onde pedimos aos alunos que pudessem dar nomes a característica do prisma pentagonal ao qual eles tinham acabado de construir. Para isso, começa-se a realizar perguntas para que os alunos começassem a construir e identificar as características da figura, utilizando a criatividade (v) para nomeálos. Pode-se perceber as estratégias em que os alunos buscavam nomear as arestas, faces, vértices e volumes. Veja o diálogo dessa etapa do professor e alunos no quadro que se segue.

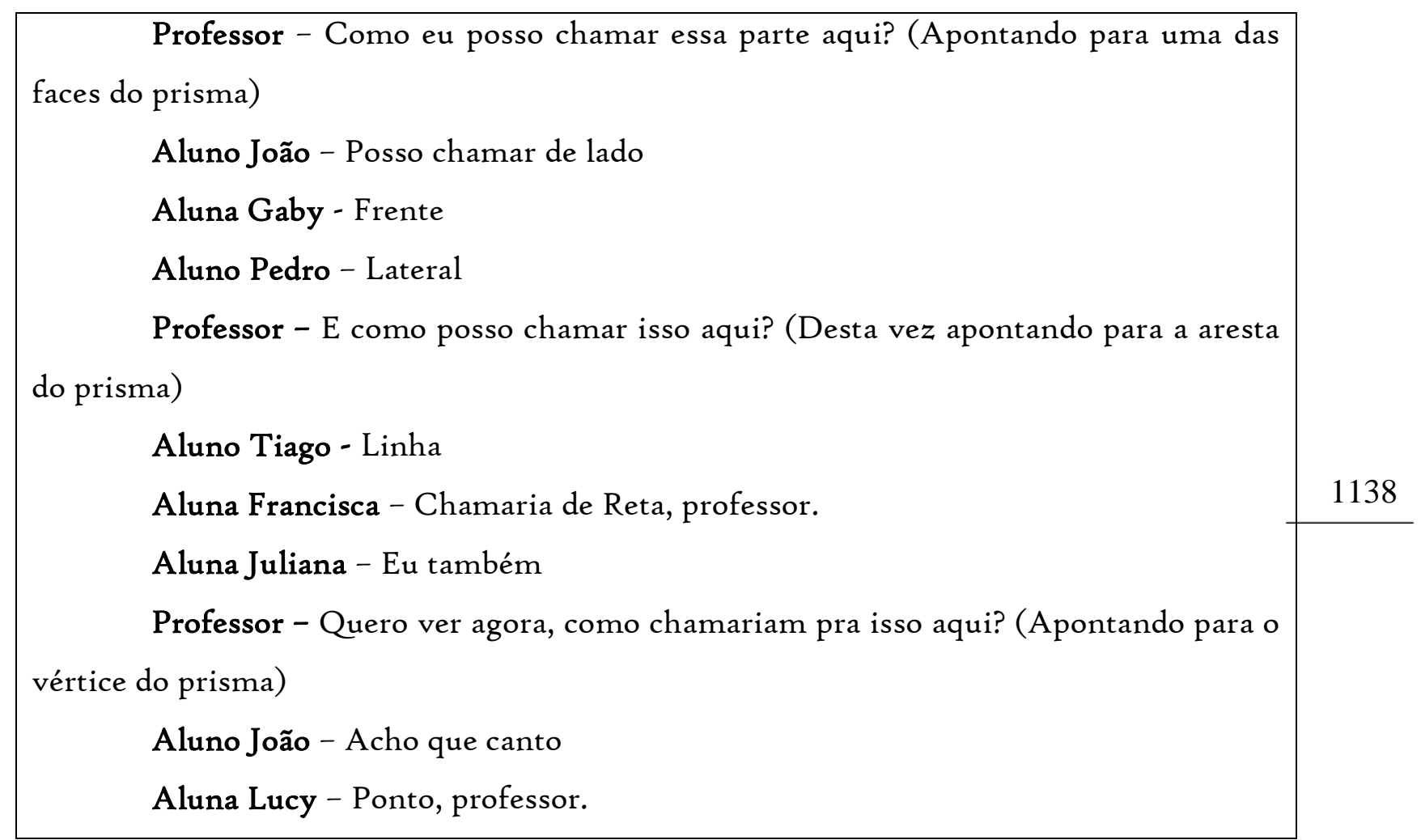

Como pode-se perceber, essa construção de conceito, contribui para a caracterização de uma figura geométrica de modo geral. Brunheira e Ponte (2018, p. 156), colocam que "a construção de definições constituiu uma ferramenta de investigação para compreender o significado que os indivíduos atribuem às definições e aceder à sua compreensão sobre os conceitos definidos". Assim sendo, pode-se analisar a presença da compreensão das regras $e$ 
conceitos (vii) durante a construção do prisma, onde os alunos passam a nomear as arestas, faces, volume e vértices mediante a linguagem natural.

Nessa acepção, ao falarem sobre o prisma pentagonal e começarem a dar nomes a essas características, começando a entender que as nomenclaturas não são por acaso, mas sim, tem relação com o seu cotidiano, ou seja, os alunos começam a analisar que "lado" de uma figura tem a mesma relação que a palavra "face", e assim, começam a contribuir para o entendimento e encontrar novos significado entre as características.

$\mathrm{Na}$ quarta etapa, busca-se formalizar o aprendizado, colocando os nomes das nomenclaturas do prisma pentagonal compreendida matematicamente e os alunos começaram a falar o que isso se caracterizava ou assemelhava com aquilo que eles estavam falando na etapa anterior, ou seja, falando a palavra "aresta", e os alunos tentavam fazer relações com aquilo que falaram e determinar o que seria uma aresta. Portanto, os alunos teriam que utilizar métodos de investigações (iv) para tentar determinar o que seria as arestas, vértices, faces e volumes.

Para essa etapa, distribuímos uma folha de tarefa, como pode-se ver na imagem I acima, e os alunos teriam que responder. Entretanto, o objetivo de distribuir as folhas era 1139 alcançar aqueles possíveis alunos que tivessem vergonha de expor suas ideias de forma espontânea, e para isso, esses alunos escreveriam suas ideias, mas ao final teriam que ler para que o restante da turma pudesse ouvir e até mesmo questionar seus argumentos. $\mathrm{O}$ autor Tudella et al (I999, p. 94) fala que esse momento de discussão é fundamental, pois proporciona "aos alunos momentos onde possam pensar e sobretudo reflectir sobre a actividade realizada. Os alunos, ao compararem diversas abordagens e ao reflectirem sobre a natureza da tarefa, compreendem melhor o significado de uma investigação matemática”.

Nesse momento da etapa, abriu-se um leque de discussão na sala de aula, os alunos começaram a trocar ideias (iv) e conjecturas perante a tarefa. Para uma melhor analise, buscase criar um quadro com alguns diálogos com a turma referente as respostas dos alunos sobre a atividade distribuída. Para uma melhor exemplificação, analisando questão por questão as respostas dos alunos, veja a seguiras respostas dos alunos sobre a primeira questão. 
Professor - O que é aresta?

Aluno Enzo - Aresta pode ser a linha que forma a figura

Aluna Gaby - É a linha que liga os pontinhos

Aluna Rayssa - Pode ser a alinha que se liga nos pontos.

Como pode-se analisar, os alunos começam a construção de conceitos matemáticos e a compreende-los, quando fazem essa relação de semelhança entre concepção cotidiana e as definições postas matematicamente, usando a linguagem própria da matemática. Lorensatti (2009, p. 90) enfatiza que a "apropriação desse conhecimento é indissociável do processo de construção do conhecimento matemático. Está compreendido, na linguagem matemática, um processo de "tradução" da linguagem naturalı para uma linguagem formalizada".

Por consequência, é notório o esforço dos alunos para traduzir a linguagem matemática presente nesse dialogo, onde tentar descrever o que seria uma aresta, como mostra nas falas dos três alunos que descrevem como uma linha. Já no diálogo que se segue referente a segunda questão da tarefa onde os alunos expuseram suas ideias, eles tentam responder que 1140 seria um vértice.

Professor - Pra vocês, o que seria um vértice?

Aluna Carol - Acho que os vértices seria o canto da figura, professor!

Aluno Pedro - também acho que seriam os pontos!

Aluno João - Esses pontos na extremidade!

Aluna Julia - Seriam os pontos que atinge os lados?!

Os alunos Pedro e João e as alunas Carol e Julia, expuseram suas conjecturas e falaram que um vértice é o canto ou o ponto da figura, vale salientar aqui a importância dos alunos desenvolveram a linguagem natural, para que depois desenvolva a linguagem matemática, 
pois essas duas linguagens são hibridas e contribuem para o processo de ensino e aprendizagem. (MENEZES, 1999)

Nesse próximo quadro, o diálogo foi referente o que seria uma face de um prisma, onde os alunos também começaram a expor seus argumentos, onde para eles, a face poderia ser a parede ou o lado da figura. Essa forma de discussão é importante, segundo o autor Tudella et al (1999, p. 95) a "reflexão permite que os processos de resolução sejam valorizados em relação aos produtos, mesmo que estes não conduzam a uma resposta final correcta", diante disso, os alunos constroem o conceito mediante ao uso do material didático, mesmo que sua resposta não seja a correta, podem, começam a chegar a um significado mutuo.

Professor - O que pode ser a face do prisma?

Aluna Paula - As paredes

Aluna Maria - são os lados

Aluno João - também acho que pode ser as paredes

Aluno Pedro - Esse lado ai (apontando para a lateral do prisma)

Nesse último diálogo voltado para a pergunta o que era um volume, os alunos tiveram dificuldades em relatar, com suas palavras o que seria. Como pode ver, apenas duas alunos tentaram descrever. Veja a tabela que se segue.

Professor - E volume, o que seria o volume?

Aluno Gabriel - É aquilo que colocamos dentro do prisma.

Aluna Rayssa - É o que fica dentro de alguma coisa, do recipiente.

Desse modo, durante essa etapa, percebe-se que os alunos tiveram dificuldade em descrever o que seria volume. Para isso, a exemplificação do que seria o volume utilizando um recipiente fechado, começando a colocar água nesse recipiente, e assim, explicando na prática que o volume seria a quantidade de espaço ocupada dentro desse recipiente. Fernando et al 
(2018, p. 03) fala que "não é possível fazer uma demonstração prática sem um dispositivo apropriado que possa comparar volumes entre sólidos e líquidos”, desta forma, também sugere o uso de protótipos para o ensino de volume, pois contribui para o processo de aprendizagem.

Já na quinta etapa, busca-se abrir espaço para que os alunos pudessem manipular o material construído, para a melhor interação sobre o que havia acabado de dialogar. Como pode ver na imagem, os alunos manipulam o sólido geométrico que eles mesmo construíram com materiais de baixo custo. Veja a imagem 4.

\section{Imagem 4 - Alunas com o prisma}

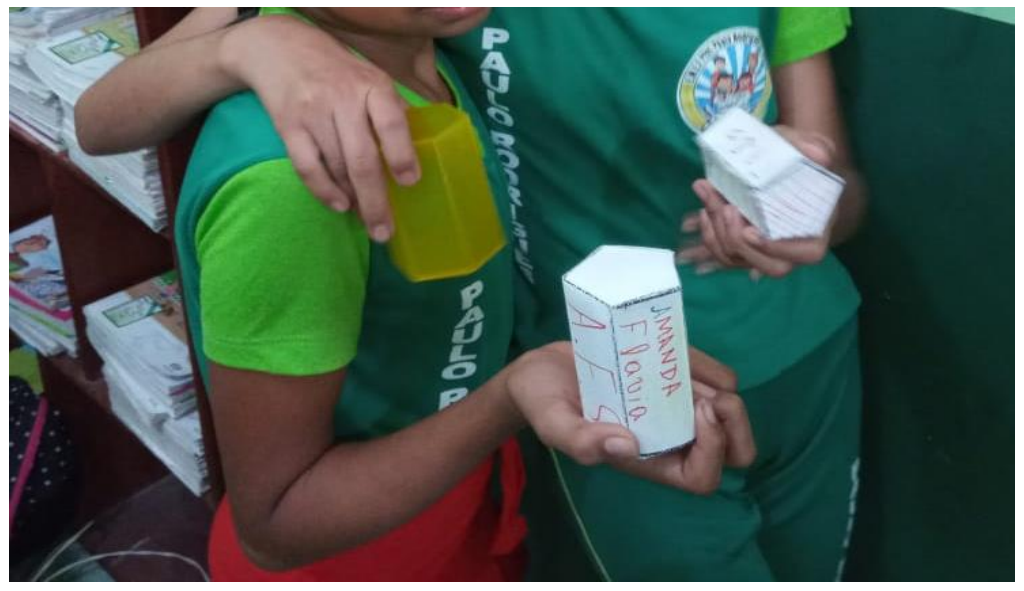

Fonte: Autores

O uso e a construção desses materiais podem contribuir para o processo de ensino e aprendizagem, a manipulação dessas figuras proporciona os alunos a alinharem a abstração com o meio físico, desta forma, aprendem de maneira prazerosa e identificam suas características e definições, auxiliando assim na construção do conceito dos elementos de um prisma pentagonal.

\section{CONSIDERAÇÕES FINAIS}

O material didático manipulável dentro da sala de aula de matemática, pode contribuir e possibilitar aos alunos o desenvolvimento no processo de construção do conhecimento, 
alinhando o saber do cotidiano ao seu redor com o saber matemático. Esse conhecimento auxilia no processo de ensino e de aprendizagem dos assuntos que envolvam o ensino de figuras da geometria, e estas figuras podem ser construídas por meio de materiais de baixo custo, como papel cartão, tesoura, régua e cola, materiais presentes dentro da sala de aula ou que são de baixo custo econômico que podem ser facilmente adquiridos.

Nesta concepção, entende que esses materiais contribuem na aprendizagem dos alunos a partir do momento que começam a manipular o material palpável na construção do sólido geométrico, e começam a dar nomes a cada característica que aparece. Os professores são fundamentais nesse processo, pois além de auxiliá-los, os professores também podem colocar pequenos desafios como pedir para que os alunos deem nomes a essas figuras entre outros.

Seguindo o raciocínio, os materiais didáticos manipuláveis vêm contribuir no processo de ensino ao auxiliar o professor no ensino de conceitos básicos matemáticos, pois, do ponto de vista dos alunos, alguns momentos teóricos nas aulas de matemática faz a aula se tornar monótona, fazendo com que o aluno perca o interesse em aprender. Sendo assim, os materiais didáticos manipuláveis, podem auxiliar no ensinar os conceitos, bem como desperta a atração

e o interesse do aluno em querer participar, deixando a aula mais satisfatória.

Contudo, a importância desses materiais de baixo custo para o ensino e aprendizado torna-se indispensável, ainda mais para escolas que não detém de recursos financeiros para apresentar novos viés de metodologias para o ensino e aprendizado dos alunos. o uso de materiais didáticos manipuláveis contribui no ensino de figuras geométricas como o prisma pentagonal que virmos no decorrer do trabalho, além de contribuir para a criticidade e reflexões dos alunos.

\section{REFERÊNCIAS}

ANANIAS, B. R.; PESSOA, C. A. S. O uso do material manipulativo e do cálculo mental na resolução de problemas de multiplicação por alunos do $3^{\circ}$ ano do ensino fundamental. Caderno do IME - Série matemática, v. 9, n. I, p. 35 - 50, 2015.

BOTAS, D.; MOREIRA, D. A utilização dos materiais didáticos nas aulas de matemática um estudo do I $^{\circ}$ ciclo. Revista portuguesa de educação, v. 26, n. I, p. 253 - 286, 2013. 
BRUNHEIRA, L.; PONTE, J. P. Definir figuras geométricas: uma experiencia de formação com futuras professoras e educadoras. Portugal: Quadrante, v. 27, n. 2, p. 133-159, 2018.

DIAS, A. S. Tarefa de exploração no estudo de prismas para alunos do $6^{\circ}$ ano do ensino fundamental. 2012. $27 \mathrm{f}$. Curso de especialização em docência na educação. Universidade Federal de Minas Gerais - Belo Horizonte, 2012.

FERNANDO, P. H. L.; AlMEIDA, A. D.; SANTANA, A. P.; PILATTI, J. Z.; GOMES, L. A.; ADONI, P.; AMARELlO, P. A. M. Ensinando as unidades de medida, metro cubico e litro, por comparação entre volume de solido e liquido para alunos do ensino fundamental II. Anais. Congresso Internacional de educação tecnológica, 2018.

FONSECA, D. O.; GUALANDI, J. H. O laboratório de ensino de matemática na formação continuada de professores que ensinam matemática. Ensino de matemática em debate, v. 7 , n. 2, p. 7I-88, 2020 .

FONSECA, H.; BRUNHEIRA, L.; PONTE, J. P. (1999). As actividades de Investigação, o professor e a aula de Matemática, Actas do ProfMat 99 (pp. 9i-ior). Lisboa: APM.

JACOBS, H. Aprendizagem da Matemática: A importância da utilização de materiais. 2 ed. Geometry, 1987.

LORENSATTI, E. J. C. Linguagem matemática e língua portuguesa: diálogo necessário na resolução de problemas matemáticos. Caxias do sul: Conjecturas, v. I4, n. 2, p. 89 - 99, 2009.

LORENZATO, S. O Laboratório de Ensino de Matemática na Formação de Professores. Campinas: Autores Associados, 2006.

LUCENA, R. S. Laboratório de ensino de matemática. Fortaleza: UAB/IFCE, p. 94, 2017.

MENEZES. L. Matemática, linguagem e comunicação. Actas do Profmat 99. Lisboa: APM, 1999.

PASSOS, C. L. B. Materiais manipuláveis como recursos didáticos na formação de professores de matemática. In: LORENZATO, S. Laboratório de Ensino de Matemática na formação de professores. Campinas: Autores Associados, p. 77-92, 2006.

PONTE. J. P. Tarefas no ensino e na aprendizagem da matemática. In: (Org.). Práticas profissionais dos professores de matemática. I ed. Lisboa: Instituto de Educação da Universidade de Lisboa, p. 13-30, 2014. 
PONTE, J. P.; GUERREIRO, A.; CUNHA, H.; DUARTE, J.; MARTINHO, H.; MARTINS, C.; MENEZES, L.; MENINO, H.; PINTO, H.; SANTOS, L.; VARANDAS, J. M.; VEIA, L.; VISEU, F. A comunicação nas práticas de jovens professores de Matemática. Revista Portuguesa de Educação, v. 20, n. 2, p. 39-74, 2007.

PONTE, J. P.; OLIVEIRA, H.; BRUNHEIRA, L.; VARANDAS, J. M.; FERREIRA, C. O trabalho do professor numa aula de investigação matemática. Quadrante, v. 7, n. 2, p. 4I-70, 1998.

PONTE, J. P. Investigações matemáticas em Portugal. Investigar em Educação, 2, p. 93-169, 2003.

RODRIGUES, J. M. S. O uso de materiais manipuláveis no entendimento de alunos de pedagogia: estudos de espaço e forma. Anais VI CONEDU... Campinas Grande: Realize Editora, 2019.

SANTOS, W. C.; COSTA, L. F. M. Construção de Materiais didáticos manipuláveis para o ensino de matemática para alunos cegos. Itapetininga: Revista Brasileira de iniciação cientifica, v. 7, n. 05, p. $22-41,2020$.

SOUSA, B. M.; SILVA, A. J. J.; SILVA, J. J. Planificações de sólidos: aplicação como intervenção pedagógica de baixo custo para o ensino de conceitos geométricos para alunos de uma escola de ensino fundamental no oeste do Pará. Rio Branco: South American Journal ofÇ 1145 basic education, technical and technological, v. 6, n. 2, p. I68- I89, 2019.

TURRIONI, A. M. S.; PEREZ, G. Implementando um laboratório de educação matemática para apoio na formação de professores. In: LORENZATO, Sérgio. Laboratório de Ensino de Matemática na formação de professores. Campinas: Autores Associados, 2006. p. 57- 76.

TUDELlA, A.; FERREIRA. C.; BERNARDO, C.; PIRES, F.; FONSECA, H.; SEGURADO, I.; VARANDAS, J. Dinâmica de uma aula com investigações. In: ABRANTES, P. et al. (Org). Investigações matemáticas na aula e no currículo. Portugal: Matemática para todos: investigações na sala de aula e Associação de professores de matemática, p. 87-96, i999.

VALE, I.; BARBOSA, A. materiais manipuláveis para aprender e ensinar geometria. BOLETIM GEPEM, v. I, n. 65, p. 3- I6, 2014. 